REVIEW

\title{
Introduction of the Taser into British policing. Implications for UK emergency departments: an overview of electronic weaponry
}

\author{
A Bleetman, R Steyn, C Lee
}

Emerg Med J 2004;21:136-140. doi: 10.1136/emj.2003.008581

The Taser is a development of the stun gun. It has recently been introduced into British policing as a "less lethal" weapon to fill the operational gap between the baton and the gun for controlling potentially dangerous and violent suspects. It is inevitable that "tasered" victims will be brought to hospitals. A review of clinical experience with electronic weaponry is presented. Suggestions for managing "tasered" subjects are provided.

See end of article for authors' affiliations

Correspondence to: Dr A Bleetman, 32 Rothwell Drive, Solihull B91 1HG, UK; bleetman@ enterprise.net

Accepted for publication 22 June 2003
$\mathrm{P}$ olice have a limited number of use of force options when confronting dangerous or violent suspects. Police officers are legally and morally required to use the lowest level of force necessary to control a situation and to deescalate at the earliest opportunity. Use of force options start with good communication skills, then escalate from unarmed physical skills (holds, restraints, strikes), deployment of incapacitant sprays, up to the use of batons. At the capacity of an officer deploying a baton, there remains only the use of a firearm. Police agencies have searched for "less lethal" weapons to fill the operational gap between the baton and the gun.

The ideal "less lethal" weapon will incapacitate a potentially dangerous person to facilitate their safe arrest, with only minimal risk of injury or death to the subject, the police officer, or bystanders. All less lethal options carry a risk, but this needs to be considered in the operational context: these weapons are designed to act as a low risk replacement for police firearms, which carry a mortality of about 50\%. ${ }^{1}$ There have been many operational examples where lives may have been saved had there been a viable alternative to shooting the suspect. ${ }^{2}$

A range of "less lethal" weapons have been evaluated by various government, forensic, and include: impact devices, (baton rounds, bean bags, rubber projectiles); water cannon; long range chemical delivery devices; electrical devices (stun guns, sticky shocker, Tasers); and distraction and disorientation devices (lasers, stun grenades, noise generation devices, malodourants, smoke, nets, foam, grease, and tranquillisers). ${ }^{3}$

From these, the Association of Chief Police Officers (ACPO) selected the Advanced Taser for present, when facing levels of threat that exceed humanitarian agencies. Recent examples of these an operational trial by firearm units of five police forces in the UK. This will inevitably result in "tasered" subjects being brought to emergency departments.

\section{THE ADVANCED TASER}

The Advanced Taser is a battery operated unit resembling a hand gun that fires two barbed electrodes on 21 foot long copper wires at $180 \mathrm{feet} / \mathrm{second}$ (fig 1). The weapon is aimed by a laser sight. The barbs attach to the subject's skin or clothing and deliver up to 50000 volts of electricity in rapid pulses over five seconds. The current can cross up to two inches of clothing. ${ }^{4}$

The Advanced Taser current causes uncontrollable muscle contraction and overwhelming pain that incapacitates the subject. The weapon can be turned off before the end of the five second default period. The barbs remain attached until removed. This allows further electrical discharges to be delivered via the copper wires should the subject resume non-compliant and threatening behaviour. The cartridge can be detached from the weapon allowing it to be used as a stun gun in close quarters.

The 26 watt Advanced Taser was developed after attempts to improve the effectiveness of an earlier 7 watt Taser system that was defeated by "focused" volunteers who were able to fight through its effects. These delivered between 40000 to 100000 volts at only 3 to $4 \mathrm{~mA}$. Trials of increasing the pulse rate and pulse power demonstrated that increases in pulse power were more effective.

The Advanced Taser delivers a sequence of half sine wave current pulses, each having a peak amplitude of about 18 amps and a duration of about 11 microseconds. ${ }^{5}$ The peak voltage output of the device is as high as 50000 volts.

\section{EFFECTS OF ELECTRICITY ON THE BODY}

Doctors working in emergency medicine are familiar with the effects and management of conventional alternating or direct current electrical injury, but most will have no experience in treating patients who have been "tasered".

Alternating current (AC) at frequencies similar to those used for domestic power distribution has a more pronounced effect on sensation, nerve, and muscle function than direct current (DC) and current at higher frequencies. ${ }^{6}$ DC and current at frequencies of more than $1000 \mathrm{~Hz}$ produce heat, while those at lower frequencies tend to generate pain and muscle contraction. 


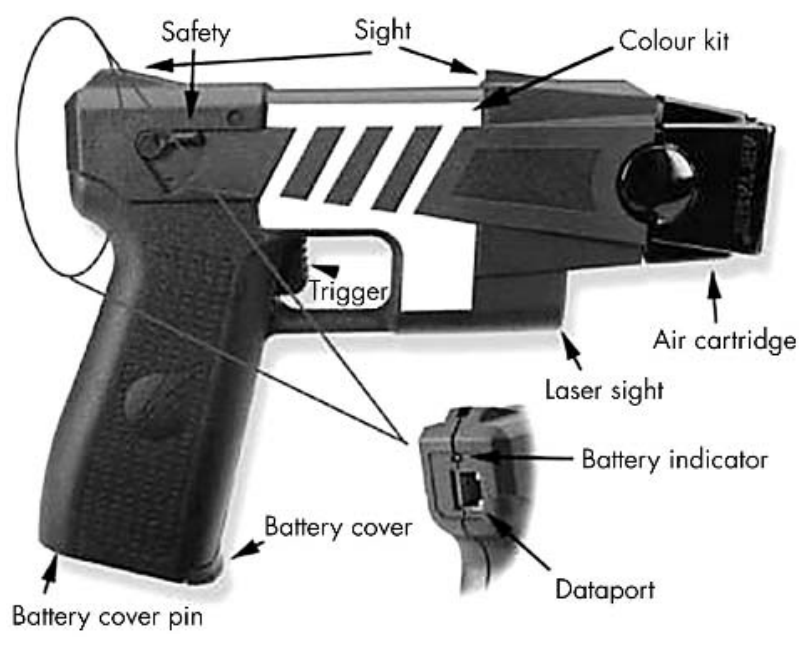

Figure 1 The Advanced Taser.

Electric fences, stun guns, and Tasers use short pulses of high voltage electricity carrying little energy, which produce a painful shock with a lesser tendency to disrupt muscular or cardiac function. ${ }^{6}$

Electricity can cause injury in three ways: the direct effect of electric current on the tissues, conversion of electrical energy to thermal energy, and blunt injury from muscle contractions or falls. ${ }^{7}$ The extent of injury after electric shock is determined by voltage, resistance, amperage, type of current, current pathway, and the duration of contact. ${ }^{7}$ The resistance to the flow of domestic electricity (low voltage, low frequency) into the body depends on the area of contact, the pressure applied, the magnitude and duration of current flow, and the presence of moisture. Skin is the primary resistor to the flow of this current into the human body. ${ }^{8}$ Skin resistance varies very widely indeed as a function of thickness, vascularity, hydration, callosity, and the area of the body to which the electricity is delivered.

High voltage DC current tends to cause a single muscle spasm, often throwing the victim from the source causing blunt trauma. ${ }^{9}$ Contact with a DC source can result in disturbances in cardiac rhythm, depending on the phase of the cardiac cycle at the moment of delivery of electricity.

The Advanced Taser delivers very high frequency electricity. It is neither pure AC nor pure DC, and is probably akin to rapid fire low amplitude DC shocks (personal communication). High frequency electrical currents tend to stay near the surface of a conductor; hence, the output of the Advanced Taser is believed to stay near the surface of the body in the skin and muscle tissue and does not penetrate into the internal organs. This is known as a Faraday shield (personal communication). In this way, the electrical delivery of the Taser, and thus its injury potential, are likely to be different from other conventional modes of electrical injury.

STUN GUNS AND THE ORIGINAL (5-7 WATT) TASER The Advanced Taser was developed from original 1970s stun gun technology. Early versions of the weapon were deployed in America in the $1980 \mathrm{~s}$ and delivered 5-7 watts. These were considered to be non-lethal to a healthy person after evaluation by the US Consumer Product Safety Commission in 1976.

While medical experience with stun guns and the original (5-7 watt) Taser has been described, there has been no published medical experience with this new more potent weapon.
The stun gun was implicated in causing skin burns with negligible adverse neurological and cardiac injury. ${ }^{10}$

One series of 16 deaths in police suspects who had been subjected to the original Taser between 1983 and 1987. ${ }^{11}$ identified that all subjects were male, aged between 20 and 40 years of age. All were known to use illicit drugs. Each was engaged in some bizarre form of behaviour on the arrival of police officers. Several had been subjected to other trauma during arrest. These included empty hand skills, batons, and firearms. In 13 of the 16, the presence of drugs was confirmed at necropsy.

One subject had pre-existing heart disease that had previously resulted in hospital admission and a recommendation for a permanent pacemaker. This subject had previously declined medical intervention for his cardiac problem. At necropsy, this subject also had significant blood concentrations of illicit drugs.

The authors suggest that these deaths shared similar characteristics to most other deaths in custody, the common threads being the presence of drugs and the subject exhibiting bizarre behaviour at the time of arrest.

These conclusions were challenged by a forensic pathologist who expressed concern that certain medical conditions, including drug use and heart disease, may increase the risk that the Taser will be lethal. ${ }^{12}$ The methods of collating and reporting the data on the series of 16 deaths were challenged. It was argued that the Taser was at least contributory in 9 of these 16 deaths and it was considered only logical that a device capable of depolarising skeletal muscle could also depolarise heart muscle and cause fibrillation under certain circumstances, particularly in those with pre-existing heart disease, psychosis, and the use of drugs including cocaine, PCP, amphetamines, and alcohol.

Another paper described a prospective series of 218 patients who had been brought to the emergency department of a Los Angeles hospital after being shot with the original Taser in the early 1980s. ${ }^{1}$ Most of these patients too had exhibited bizarre behaviour at the time of their arrest and most had taken drugs or alcohol on the day of their arrest; $15 \%$ had pre-existing medical problems. Three of these patients arrived at hospital in cardiac arrest: two of whom had no medical history and went into cardiac arrest at 5 and 15 minutes after being shot with the Taser. The third had a pre-existing cardiac history and went into respiratory arrest followed by cardiac arrest 25 minutes after being shot with the Taser. All three had high levels of PCP in their blood. PCP toxicity was the cited cause of death in all three.

Thirty eight per cent had associated injuries related to their violent behaviour. Mild rhabdomyolysis had occurred in $1 \%$ of patients. It could not be determined if this developed secondary to PCP misuse or to the muscular contractions caused by the Taser. One patient developed a testicular torsion after being "tasered", and another claimed that he had become sterile. "Tasered" patients spent an average of 6.5 hours in the emergency department. Two thirds had a psychiatric evaluation and half of these were subsequently admitted to a psychiatric facility. Ninety two per cent of patients had no recollection of being "tasered".

The author drew a number of conclusions:

- Many subjects need medical treatment for minor trauma as they usually fall when "tasered".

- Most are seen in the emergency department for barb removal.

- The pre-existing injuries and toxic conditions leading to the patient being "tasered" are the major problems requiring medical treatment.

- Three patients died, probably because of cardiac arrhythmia in a pre-existing irritable heart. All had toxic 
concentrations of PCP in their blood and one had confirmed pre-existing disease. The Taser could not be held solely responsible for their deaths.

- The death rate in these patients was no higher than that reported for PCP toxicity alone.

Another author concluded that most "tasered" subjects had been under the influence of PCP, making it difficult to draw conclusions. Concern was expressed over the potential for injury to the eyes and vulnerable anatomy by the barbs. The author explained that the calculated electrical output of the Taser (which involved some unsubstantiated electrical engineering assumptions) was under the thresholds for causing cardiac fibrillation and asphyxia. ${ }^{13}$ However, the effects of the Taser on people with coronary heart disease, conduction defects, pre-existing arrhythmias, pacemakers, or those under the influence of alcohol or other drugs were unknown. Concerns also identified included the potential effect of the Taser disrupting the software of cardiac pacemakers or disrupting the pacemaker cable leading to cardiac arrhythmias.

The same author ${ }^{14}{ }^{15}$ suggested an approach to "tasered" victims that involved ECG and admission of these patients for observation, to exclude cardiac complications. It was suggested that the management of subjects shot with the original Taser should include treatment for the condition that caused them to exhibit bizarre and violent behaviour leading to deployment of the weapon. ${ }^{16}$

A case of Taser dart ingestion, which passed through the gut without complication, was also described. ${ }^{17}$

\section{EXPERIENCE WITH THE NEW (26 WATT) ADVANCED TASER}

There has been no published medical literature on the Advanced Taser, which has been deployed in North American police forces since 1999. It is estimated that there have been about 10000 operational uses of the device and 30000 deployments on "volunteers" during training. ${ }^{18}$ This includes the authors of this paper. We have been "tasered" on several occasions. The device causes overwhelming pain and inability to move. It causes an "adrenaline rush" and the desire for the barbs to be removed. Consciousness is maintained throughout. There have been no after effects.

A database of Taser use has been maintained by several US police forces and the Taser company. While there is no official statutory reporting system for Taser use and no independent mechanism for verification, there are 2050 filed case reports of field uses. The company estimates that only one in five deployments of the Advanced Taser are reported to the company by police forces. ${ }^{19}$ Clearly, these methods of collating field reports and outcomes may well incur bias.

Concerns have been raised by humanitarian groups that several recent deaths in custody in the United States were directly caused by use of the Advanced Taser. However, the coroners deemed that the application of Taser was not linked to these deaths and were comparable to other deaths in police custody. ${ }^{20}$

Examination of the Taser company database revealed that 366 of 2050 tasered subjects required more than one fivesecond cycle for officers to gain control. Of the 2050 reports, no injuries were reported in 1630 subjects. Of the remainder "minor" injuries occurred in 222, "moderate" in 23, "severe" in 13, and "unspecified" in 162 reports. The severity of injury is based on the perception of the reporting police officer, not on any recognised injury severity scoring system.

Information also included injuries sustained by police officers deploying the weapon.

Ninety nine of these were reported as "minor", 7 "moderate", 2 "severe", and 114 "non-specified".
Altogether 1828 were uninjured. Injuries to officers were predominantly from the circumstances of the arrest and not attributable to the Taser.

\section{MEDICAL IMPLICATIONS}

Until clinical experience with this new device is published, it is only possible to draw general conclusions about the relative safety of this device. Clinicians need to consider the relative safety of the Taser to the potential injury from firearms and note that in about 40000 uses in volunteers and operational deployment there have been only four reported deaths.

There are several ways that the Taser might cause injury.

\section{Electrical}

The damped train of sine waves behaves differently from conventional AC or DC current. There is no evidence to date that this form of electrical delivery causes interference with cardiac or neurological function in the 30000 volunteers or in the reported operational uses. None of the volunteers required hospital treatment or have reported any long term adverse effects. American laboratory experimenters failed to induce cardiac arrhythmias on dog hearts with direct application of the Advanced Taser. ${ }^{21}{ }^{22}$ It has been postulated that a Faraday shield will prevent direct conduction into nerves and muscles as conventional electrical delivery tends to do.

Concerns remain over the potential for Tasers to cause dysfunction of pacemakers and implanted defibrillators.

\section{Barb strikes}

The Taser barbs are $4 \mathrm{~mm}$ in length and are designed to stick in skin or clothing and not fall out (fig 2). Police officers are taught to remove them by stretching the surrounding skin and tugging sharply. The $4 \mathrm{~mm}$ depth is not deep enough to threaten internal organs or cause a pneumothorax. ${ }^{23}$ There is one case report of a barb from an older type of Taser that was swallowed by a subject. ${ }^{17}$ This did not result in an adverse outcome and did not require surgical intervention. There is a risk that these barbs may strike vulnerable areas such as the eyes, the mouth, genitalia, and perhaps large blood vessels in the neck and the groin. These may require medical assessment and management.
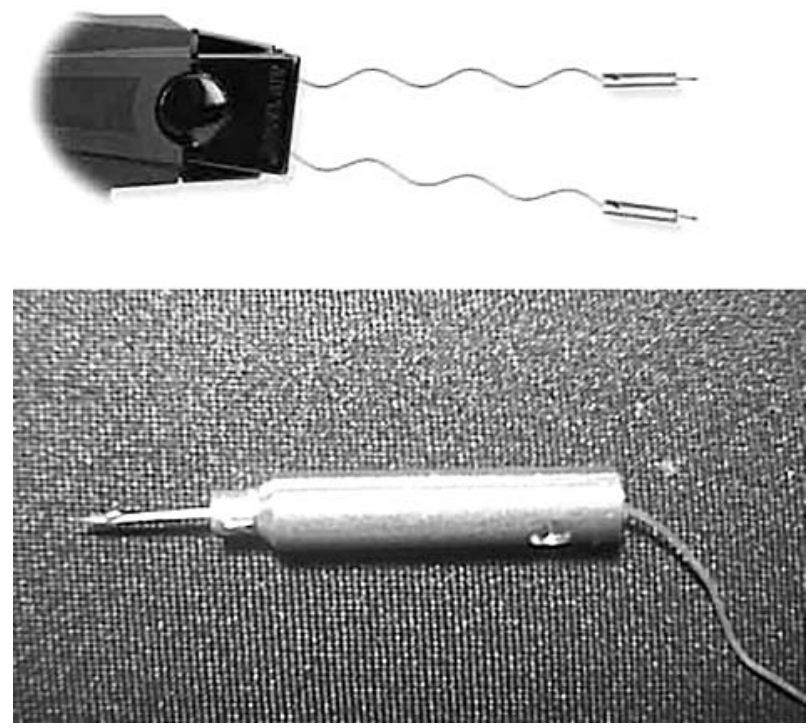

Figure 2 Taser barbs. 


\section{Burns}

Several papers have described minor burns in association with old Taser barb strikes. These have been superficial and unlikely to result in permanent scarring. ${ }^{10}$

In operational trials conducted by the Home Office, the current discharged through the Taser barbs resulted in the ignition of a mannequin soaked in four cans of CS spray. Smaller quantities of CS spray did not ignite. ${ }^{3}$ It is therefore conceivable that a subject who has been subjected to CS spray may sustain burns if subsequently shot with the Advanced Taser.

\section{Indirect injury}

The Advanced Taser incapacitates the subject who invariably falls in an uncontrolled manner. This can be expected to result in trauma, particularly if the subject has been "tasered" at an elevation above the ground.

\section{Pregnancy}

A single case report describes a spontaneous abortion in a female drug misuser in early pregnancy (8-10 weeks). She had reportedly not taken drugs in the seven days before the exposure to the (original) Taser. The miscarriage occurred one day after being "tasered". ${ }^{24}$ No conclusive link with the Taser was proved but caution must be exercised in pregnant subjects presenting to hospital after exposure to the Taser.

\section{Epilepsy}

To date, there have been no published reports of seizures associated with Taser use.

\section{Pre-arrest condition and death in custody}

One author concluded that the pre-existing injuries and toxic conditions leading to the patient being tasered are the most important problems requiring medical treatment after Taser use. It has also been suggested that "tasered" victims who die in custody were at risk of death anyway because of these risk factors. In the four reports of death in custody after use of the Advanced Taser no direct association with Taser use was implicated. Deaths in custody occur at the rate of about once a week in the UK. After introduction of the Advanced Taser we will continue to see deaths in custody. Close scrutiny of this population will be required to determine if Tasered victims appear disproportionately.

\section{Other issues}

Stun guns and other electronic weaponry have reportedly been used for interrogation and torture. ${ }^{25}$ In a paper presented by Amnesty International, torture victims reported immediate effects including severe pain, loss of muscle control, convulsions, fainting, and loss of sphincter control. The longer term effects reportedly included muscle stiffness, impotence, scarring, and post-traumatic stress disorder.

There is the possibility that some will claim post-traumatic stress disorder, torture, convulsions, miscarriage, chronic pain, and others after exposure to the Taser.

Some patients will make claims for adverse physical and psychological effects after having the taser used on them. Clear causation will be very difficult to prove given the paucity of clinical evidence.

\section{MANAGEMENT OF "TASERED" PATIENTS IN EMERGENCY DEPARTMENTS}

Based on the limited evidence and American experience with electronic weaponry, the following suggestions for management of these patients attending emergency departments are presented:

- Most healthy subjects may be safely discharged after barb removal and routine history and examination.
- Important points in the history will include known cardiac disease including implanted pacemaker or defibrillator, pregnancy, drug or alcohol intoxication, bizarre behaviour at the time of arrest, other psychiatric disturbance, or coincidental medical problems.

- Physicians will need to look closely for direct injury from the barbs or indirect injury from falls.

- An ECG may be appropriate in those with chest pain, palpitations, or cardiac history.

- Most patients will complain of muscle aches and anxiety, which by themselves require no specific management.

- There are likely to be small puncture wounds and minor burns at the barb sites. On occasion medical intervention will be required if the barbs are not removed easily, if the barb tips break off in the skin, or if the barbs have struck vulnerable areas (for example, mouth, eyes, neck, groin). Clinical judgment will be required in these circumstances.

\section{CONCLUSIONS}

There is a no independent medical literature on the effects of the new Advanced Taser. It seems that the device is essentially safe on healthy people.

Accident and emergency staff in the UK can expect to treat patients who have experienced the Advanced Taser after its introduction into UK policing. Sharing of experience will be beneficial to broaden knowledge of the safety profile of the weapon.

It is worth remembering that the Advanced Taser is to be used only as an alternative to firearms and any outcome measures should be considered in this context.

Most healthy tasered subjects can therefore be safely discharged after complete barb removal.

Further safety information is available from http://www. thetaser.co.uk/index.php?zone $=$ public\&page $=$ safetyfacts

\section{Authors' affiliations}

A Bleetman, R Steyn, C Lee, Emergency Department, Birmingham Heartlands Hospital, Birmingham, UK

Funding: none declared.

Conflicts of interest: Bleetman and Steyn have previously conducted a financed literature review for Taser International. Neither have any contractual relationship with the company or the success of the product.

\section{REFERENCES}

1 Ordog GJ, Wasserberger J, Schlater T, et al. Electronic gun (Taser) injuries. Ann Emerg Med 1987; 16:73-8.

2 Northamptonshire Police Authority. Taser operational scenario trials. Northampton: Northamptonshire Police, 2020.

3 Donnelly T. Less lethal technologies: initial prioritisation and evaluation. Police Scientific Development Branch. London: Home Office publication No 12/01.

4 Taser International. Taser promotional literature. (http://www.taser.com).

5 Taser International. Letter from Professor Harrison from the Department of Electronics, Carleton University, Canada (supplied by Taser International) (http://www.taser.com).

6 Odell M. The human body as an electric circuit. Journal of Clinical Forensic Medicine 1997;4:1-6.

7 Jain S, Bandi V. Electrical and lightning injuries. Crit Care Clin 1999;15:319-31.

8 Walpole BG. Electric shock. Aust Fam Physician 1989;18:1252-6.

9 Cooper MA. Emergent care of lightning and electrical injuries. Semin Neurol 1995; 15:268-78.

10 Frechette $\mathbf{A}$, Rimsa ME. Stun gun injury: a new presentation of the battered child syndrome. Pediatrics 1992;89:898.

11 Kornblum RN, Reddy SK. Effects of the Taser in fatalities involving police confrontation. J Forensic Sci 1991;36:434-8.

12 Allen TB. Discussion of effects of the taser in fatalities involving police confrontation. J Forensic Sci 1992;37:956-8.

13 Koscove EM. The Taser weapon: a new emergency medicine problem. Ann Emerg Med 1985;14:1205-8.

14 Koscove E. The Taser: research, patients, and language (Tom Swift found). $J$ Emerg Med 1988;6:343-4.

15 Koscove E. Taser power. Ann Emerg Med 1987;16:1190. 
16 Fish R. Electric shock, part III: deliberately applied electric shocks and the treatment of electric injuries. J Emerg Med 1993;11:599-603.

17 Koscove EM. Taser dart ingestion. J Emerg Med 1987;5:493-8.

18 Taser International. Minutes of an international less lethal weaponry meeting in Brussels, 2002 (http://www.taser.com).

19 Taser deployment database maintained by Taser International. (http:// www.taser.com).

20 Thurston County Coroner's Office, December 2002 (http://www.taser.com).

21 Panescu D, Webster JG, Stratbucker RA. A nonlinear electrica-thermal model of the skin. IEEE Trans Biomed Eng 1994;41:672.
22 Panescu D Webster JG Stratbucker RA. A nonlinear finite element model of the electrode-electrolyte-skin system. IEEE Trans Biomed Eng 1994;41:681.

23 Bleetman A, DyerJ. Ultrasound assessment of the vulnerability of the internal organs to stabbing: determining safety standards for stab-resistant body armour. Injury 2000;8:609-12

24 Mehl LE. Electrical injury from Tasering and miscarriage. Acta Obstet Gynecol Scand 1992; $71: 118-23$.

25 Welsh J. Electroshock torture and the spread of stun technology. Lancet 1997:349:1247.

\section{Clinical Evidence - Call for contributors}

Clinical Evidence is a regularly updated evidence based journal available worldwide both as a paper version and on the internet. Clinical Evidence needs to recruit a number of new contributors. Contributors are health care professionals or epidemiologists with experience in evidence based medicine and the ability to write in a concise and structured way.

\section{Currently, we are interested in finding contributors with an interest in} the following clinical areas:

Altitude sickness; Autism; Basal cell carcinoma; Breast feeding; Carbon monoxide poisoning; Cervical cancer; Cystic fibrosis; Ectopic pregnancy; Grief/bereavement; Halitosis; Hodgkins disease; Infectious mononucleosis (glandular fever); Kidney stones; Malignant melanoma (metastatic); Mesothelioma; Myeloma; Ovarian cyst; Pancreatitis (acute); Pancreatitis (chronic); Polymyalgia rheumatica; Post-partum haemorrhage; Pulmonary embolism; Recurrent miscarriage; Repetitive strain injury; Scoliosis; Seasonal affective disorder; Squint; Systemic lupus erythematosus; Testicular cancer; Varicocele; Viral meningitis; Vitiligo However, we are always looking for others, so do not let this list discourage you.

\section{Being a contributor involves:}

- Appraising the results of literature searches (performed by our Information Specialists) to identify high quality evidence for inclusion in the journal.

- Writing to a highly structured template (about 2000-3000 words), using evidence from selected studies, within 6-8 weeks of receiving the literature search results.

- Working with Clinical Evidence Editors to ensure that the text meets rigorous epidemiological and style standards.

- Updating the text every eight months to incorporate new evidence.

- Expanding the topic to include new questions once every 12-18 months.

If you would like to become a contributor for Clinical Evidence or require more information about what this involves please send your contact details and a copy of your CV, clearly stating the clinical area you are interested in, to Claire Folkes (cfolkes@bmigroup.com).

\section{Call for peer reviewers}

Clinical Evidence also needs to recruit a number of new peer reviewers specifically with an interest in the clinical areas stated above, and also others related to general practice. Peer reviewers are health care professionals or epidemiologists with experience in evidence based medicine. As a peer reviewer you would be asked for your views on the clinical relevance, validity, and accessibility of specific topics within the journal, and their usefulness to the intended audience (international generalists and health care professionals, possibly with limited statistical knowledge). Topics are usually 2000-3000 words in length and we would ask you to review between 2-5 topics per year. The peer review process takes place throughout the year, and our turnaround time for each review is ideally 10-14 days.

If you are interested in becoming a peer reviewer for Clinical Evidence, please complete the peer review questionnaire at www.clinicalevidence.com or contact Claire Folkes(cfolkes@bmigroup.com). 